$\underline{\text { Miscellanea }}$

\title{
A snapshot of the pioneering personalities in the Paediatric Scenario in Sri Lanka
}

\author{
*Sanath P. Lamabadusuriya ${ }^{1}$ \\ Sri Lanka Journal of Child Health, 2016; 45(4): 294-296 \\ DOI: http://dx.doi.org/10.4038/sljch.v45i4.8187
}

(Key words: Pioneering personalities, paediatric scenario, Sri Lanka)

The Lady Ridgeway Hospital (LRH) for Children is the premier, exclusively paediatric hospital, in Sri Lanka. It was opened in 1910 and named after the former First Lady, Lina Ridgeway, the wife of the former British Governor of Ceylon, the name used to describe this resplendent island at that time. LRH is now, arguably, the largest Children's Hospital in the world with a bed strength of over 1100 .

LRH paved the way for the development of Paediatrics in the country. It is with a tremendous sense of nostalgia that I wish to record, in the chronological order of assumption of duties, the Specialist Consultant Paediatricians who were in charge of the different units of LRH over many a decade and set up a platform for the development of paediatrics in the country. This document is an addendum/appendix to the chapter on the "History of Paediatrics in Sri Lanka" of the book History of Medicine in Sri Lanka, Second Edition, published by the Sri Lanka Medical Association.

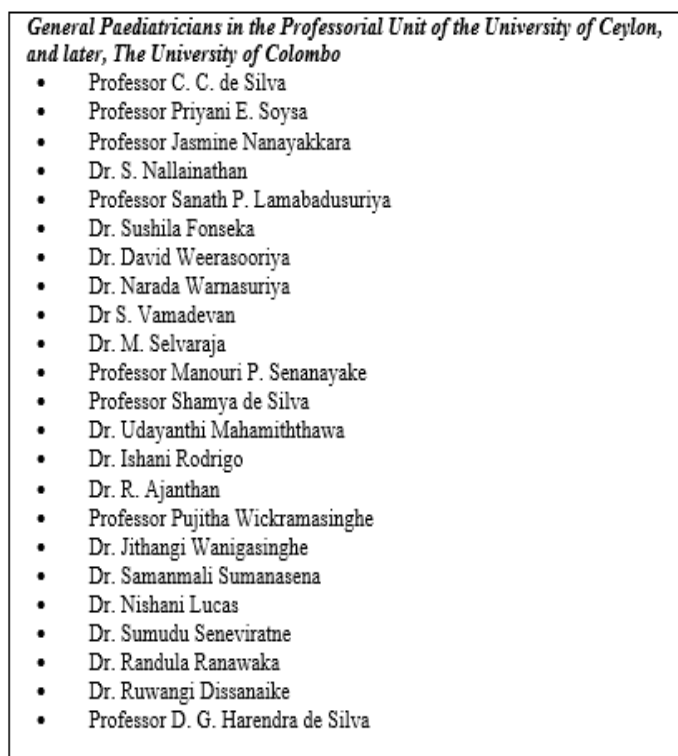

Box 1: General Paediatricians in Professorial Unit

${ }^{1}$ Emeritus Professor of Paediatrics, University of Colombo

*Correspondence: sanathp.lama@gmail.com
The list of General Paediatricians in the Professorial Unit of the University of Ceylon and later, the University of Colombo is shown in Box 1.

The list of General Paediatricians in the Ministry of Health Units is shown in Box 2.

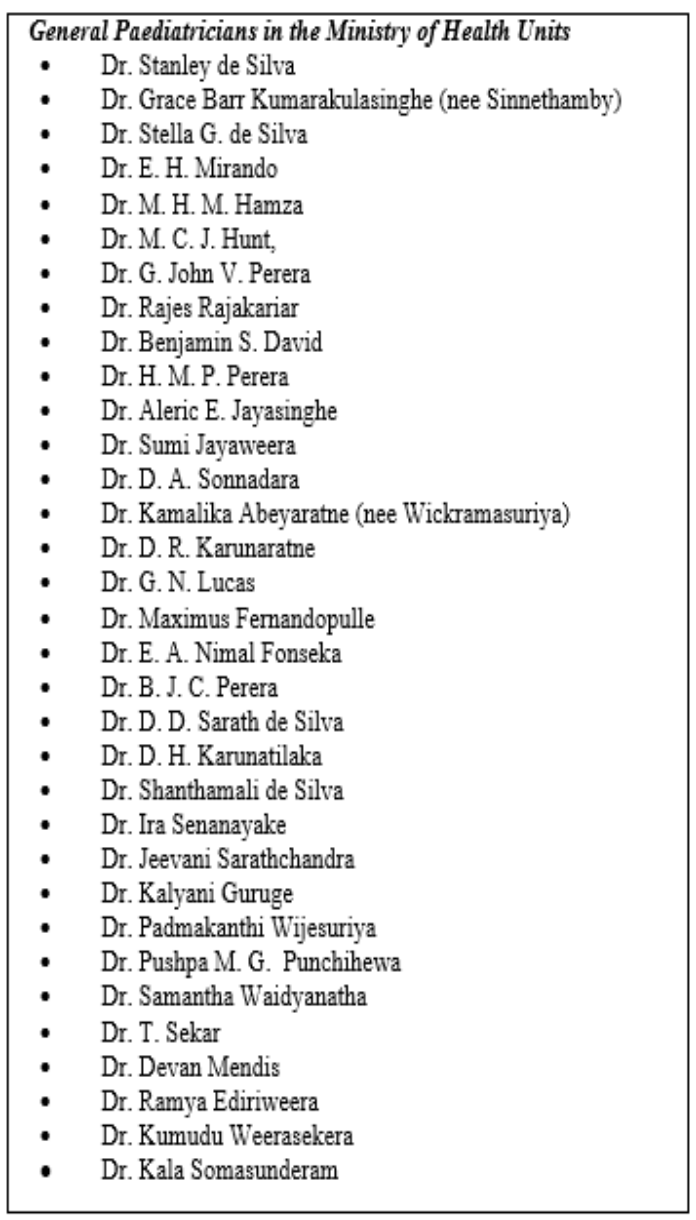

Box 2: General Paediatricians in Ministry of Health Units

Following the establishment of the Lady Ridgeway Hospital, steps were taken to establish paediatric units in the rest of the country. The pioneers that set up Paediatric Units in the hospitals of the rest of the country are shown in Box 3. 


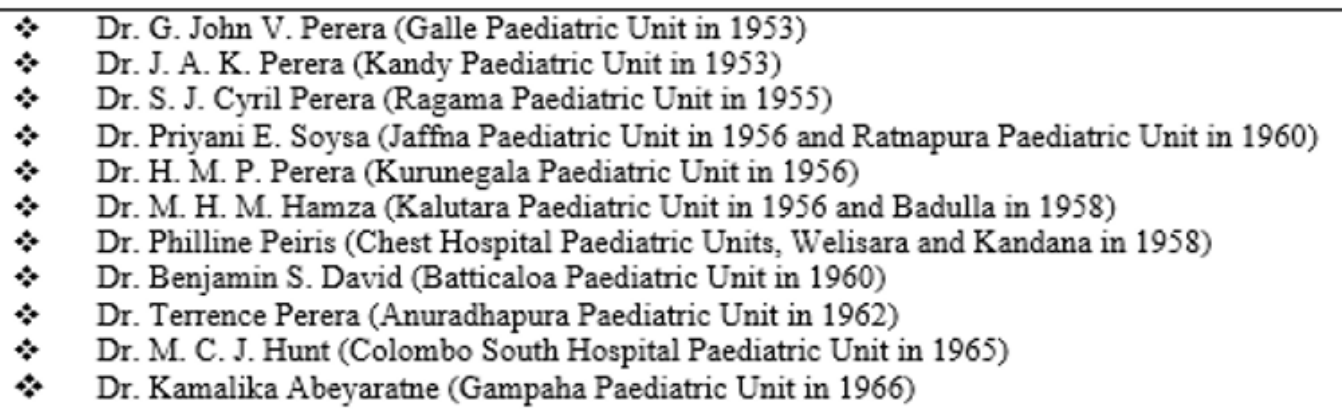

Box 3: Pioneers that set up Paediatric Units in the hospitals of the rest of the country

Then came the stage of ultra-specialty development at LRH. Pioneers in those ventures are listed in Boxes 4-8.

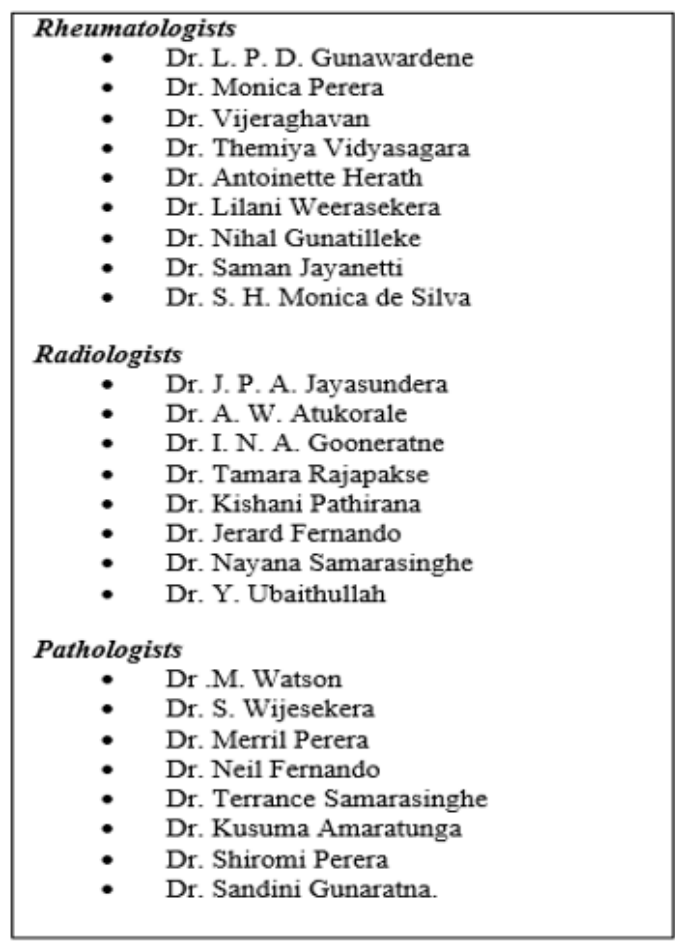

\section{Box 4}

Haematologists
- $\quad$ Dr. Sudharma Vidyathilaka
Dr. Mala Jayatilleke.
- Dr. Iresha Jasinge
Microbiologists
- Dr. Velayuthapillai
Dr. Kumudu Karunaratne
Plastic Surgeons
- Dr. Romesh Gunasekera
Neonatologists
- Dr. Ramya de Silva
Paediatric Dermatologists
- Professor Jayamini Seneviratne

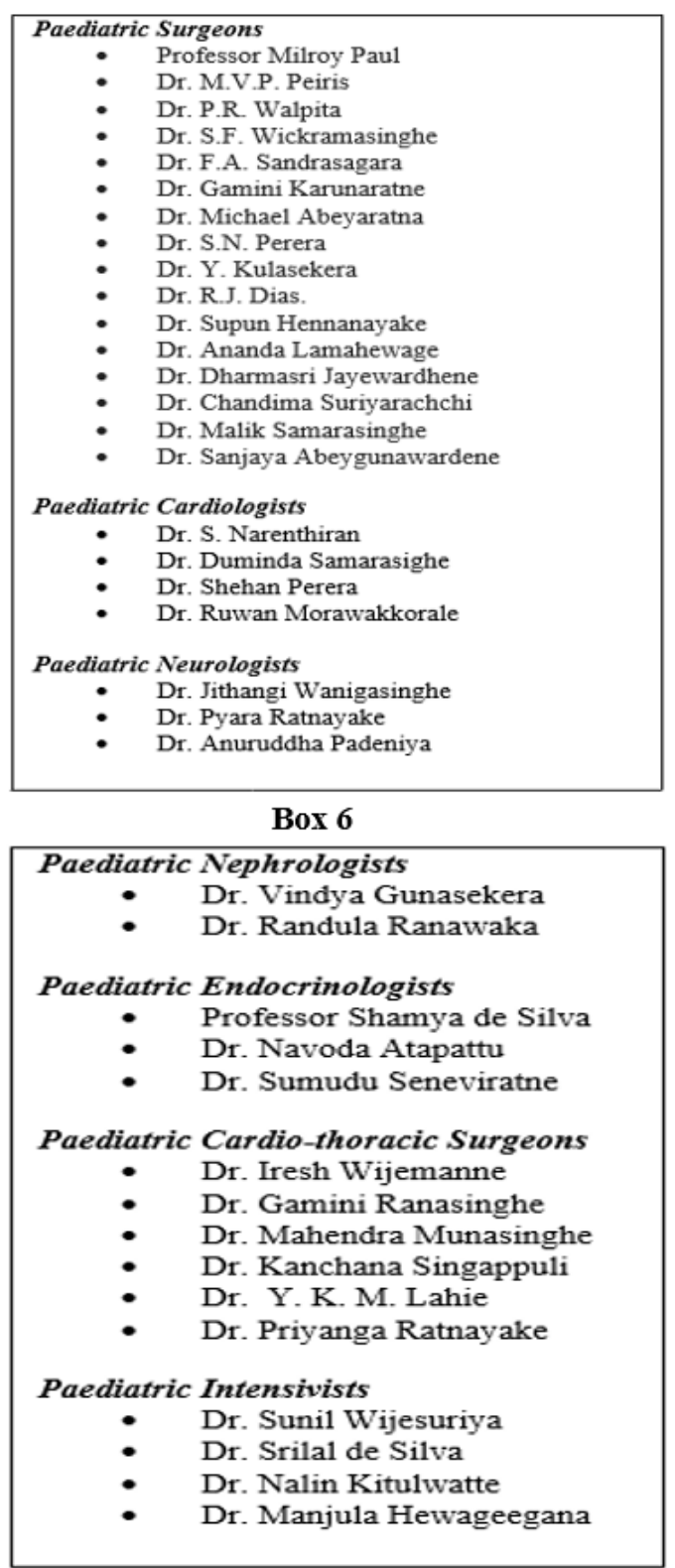

Box 7 


\section{Child Psychiatrists}

- Dr. Anula Nikapotha

- Professor Hemamali Perera

- Dr. Buddhi Karunatilaka

- Dr. Swarna Wijetunga.

- Dr. Sudarshani Seneviratne,

Orthopaedic Surgeons

- Dr. Udai de SILVA

- Dr. Marius de Almeida

- Dr. Nandana Dassanaike

- Dr. Sunil Wijesinghe

\section{Box 8}

The administrators who played a pioneering role at LRH from the 1950s up to date are shown in Box 9.

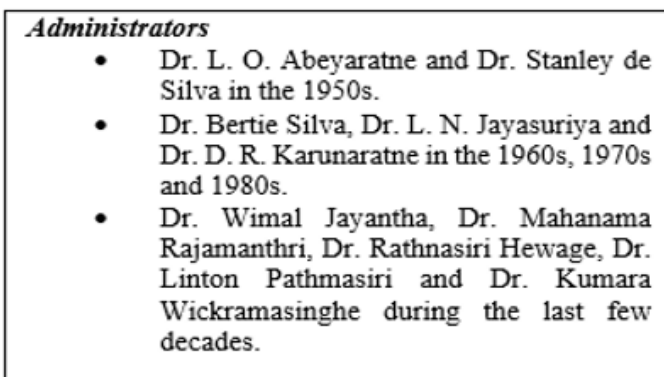

Box 9: Administrators at LRH

The list of Board Certified Specialists outside LRH are shown in Boxes 10 and 11.

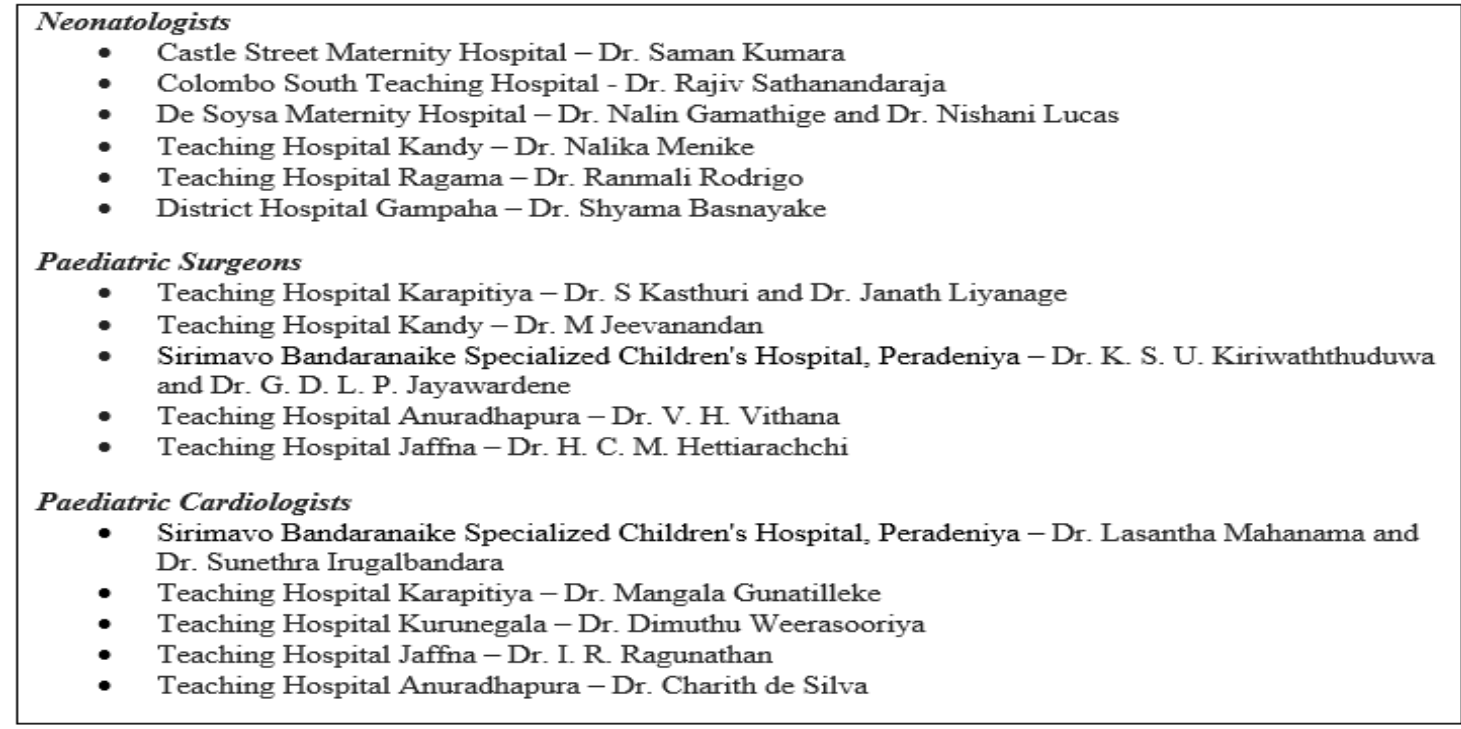

Box 10

\begin{tabular}{|l} 
Paediatric Neurologists \\
- Teaching Hospital Karapitiya - Dr. Gamunu Hewavitharana \\
- Teaching Hospital Kandy - Dr. Jagath Munasinghe \\
- Telombo South Teaching Hospital - Dr. Saraji Wijesekera \\
Paediatric Nephrologists \\
- Teaching Hospital Kurunegala - Dr. Sanjaya Fernando \\
- Teaching Hospital Karapitiya - Dr. Harshani Dharmawardene \\
Paediatric Intensivists \\
- Sirimavo Bandaranaike Specialized Children's Hospital, Peradeniya - Dr. M. A. M. Faizal \\
Paediatric Endocrinologists \\
- Sirimavo Bandaranaike Specialized Children's Hospital, Peradeniya - Dr. Nimasiri Ginige \\
Paediatric Psychiatrists \\
- Sirimavo Bandaranaike Specialized Children's Hospital, Peradeniya - Dr. Rasika Perera
\end{tabular}

Box 11

The author wishes to tender his apologies, in advance, if any name or names have been inadvertently left out and assures the readership that it is solely unintentional. 